Full version is available at https://link.springer.com/chapter/10.1007/978-3-319-66984-7 10

\title{
TeXt Segmentation teChNiQues: A CRITICAL
}

\section{REVIEW}

\section{Irina Pak and Phoey Lee Teh}

\author{
Department of Computing and Information Systems, Sunway University, Bandar Sunway, \\ Malaysia \\ I.Pak \\ e-mail: irina.p@imail.sunway.edu.my \\ P.L. Teh \\ e-mail: phoeyleet@sunway.edu.my
}

Department of Computing and Information Systems,

Sunway University, Bandar Sunway, Malaysia

irina.p@imail.sunway.edu.my, phoeyleet@sunway.edu.my

Abstract Text segmentation is widely used for processing text. It is a method of splitting a document into smaller parts, which is usually called segments. Each segment has its relevant meaning. Those segments categorized as word, sentence, topic, phrase or any information unit depending on the task of the text analysis. This study presents various reasons of usage of text segmentation for different analyzing approaches. We categorized the types of documents and languages used. The main contribution of this study includes a summarization of 50 research papers and an illustration of past decade (January 2007- January 2017)'s of research that applied text segmentation as their main approach for analysing text. Results revealed the popularity of using text segmentation in different languages. Besides that, the "word" seems to be the most practical and usable segment, as it is the smaller unit than the phrase, sentence or line. 


\section{Introduction}

Text segmentation is process of extracting coherent blocks of text [1]. The segment referred as "segment boundary" [2] or passage [3]. Another two studies referred segment as subtopic [4] and region of interest [5]. There are many reasons why the splitting document can be useful for text analysis. One of the main reasons is because they are smaller and more coherent than whole documents [3]. Another reason is each segment is used as units of analysis and access [3]. Text segmentation was used to process text in emotion extraction [6], sentiment mining [7][8], opinion mining [9][10], topic identification [11][12], language detection [13] and information retrieval [14]. Sentiment analyzing within the text covers wide range of techniques, but most of them include segmentation stage in text process. For instance, Zhu et al. [15] used segmentation in his model to identify multiple polarities and aspects within one sentence. There are studies that applied tokenization in the semantic analysis to increase the probability of obtaining the useful information by processing tokens. For example, the study of Gan at al. [16] applied tokenization in their proposed method where semantics were used to improve search results for obtaining more relevant and clear content from the search. Later, Gan and Teh [17] used technique similar to segmentation where information is organized into segments called facet and values in order to improve search algorithm. Another study of Duan at al. [18] applied text segmentation and then tokenization to determine aspects and associated features. In other words, tokenization is also text segmentation because they are apparently a similar process. That is splitting text into words, symbols, phrases, or any meaningful units named as a token.

This paper reviews different methods and reasons of applying text segmentation in opinion and sentiment mining, language detection and information retrieval. The target is to overview of text segmentation techniques with brief details. The contribution of this paper includes the categorizations of recent articles and visualization of the recent trend of research in the opinion mining and related areas, such as sentiment 
analysis and emotion detection. Also in pattern recognition, language processing, and information retrieval. Next section of this paper explains the scope and method used to review the past studies. Section 3 discusses the results of summarized articles. Section 4 contains a discussion on results. Lastly, section 5 concludes this paper.

\section{Review Method}

The review process of the articles includes publications from the past ten years. Fifty journals and conferences in total were evaluated. These articles implemented text segmentation in their main approaches. Fifty articles are summarized in Table 1 in next section.

In order to make it clear content of the Table 1 , here is breakdown the column by column. The first column of the table refers to the year of the article. Next column includes the references of study. In the following column, there is a brief description of the study. There are different types of segments used in their study, it includes: 1) topic, 2) word, 3) sentence etc. Type of segment commonly selected based on their analyzing targets and specifications. The fourth column listed the type of segment used in the assessed study. The evaluation of each study has applied different sets of data or documentations. They can be categorised as: 1) corpus, 2) news, 3) articles, 4) reviews, 5) datasets etc. We listed it in the fifth column. The sixth column describes the reason for applying the text segmentation study. The last column specifies those language(s) used in those sets of documentations(s).

\section{Results}

Following, we present the summarized review in Table 1. 
Table 1. Summarisation of the fifty articles applied text segmentation in their studies.

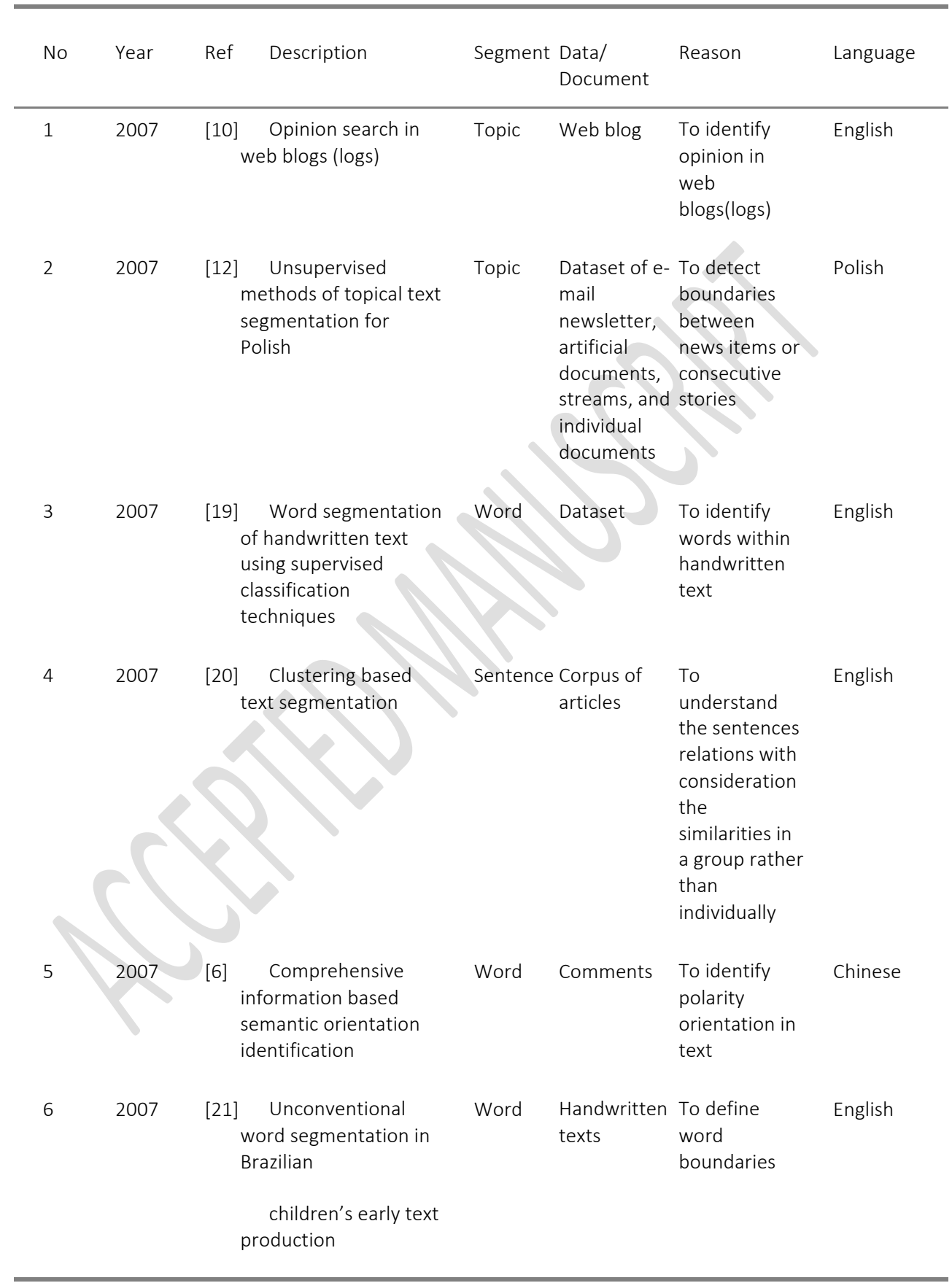




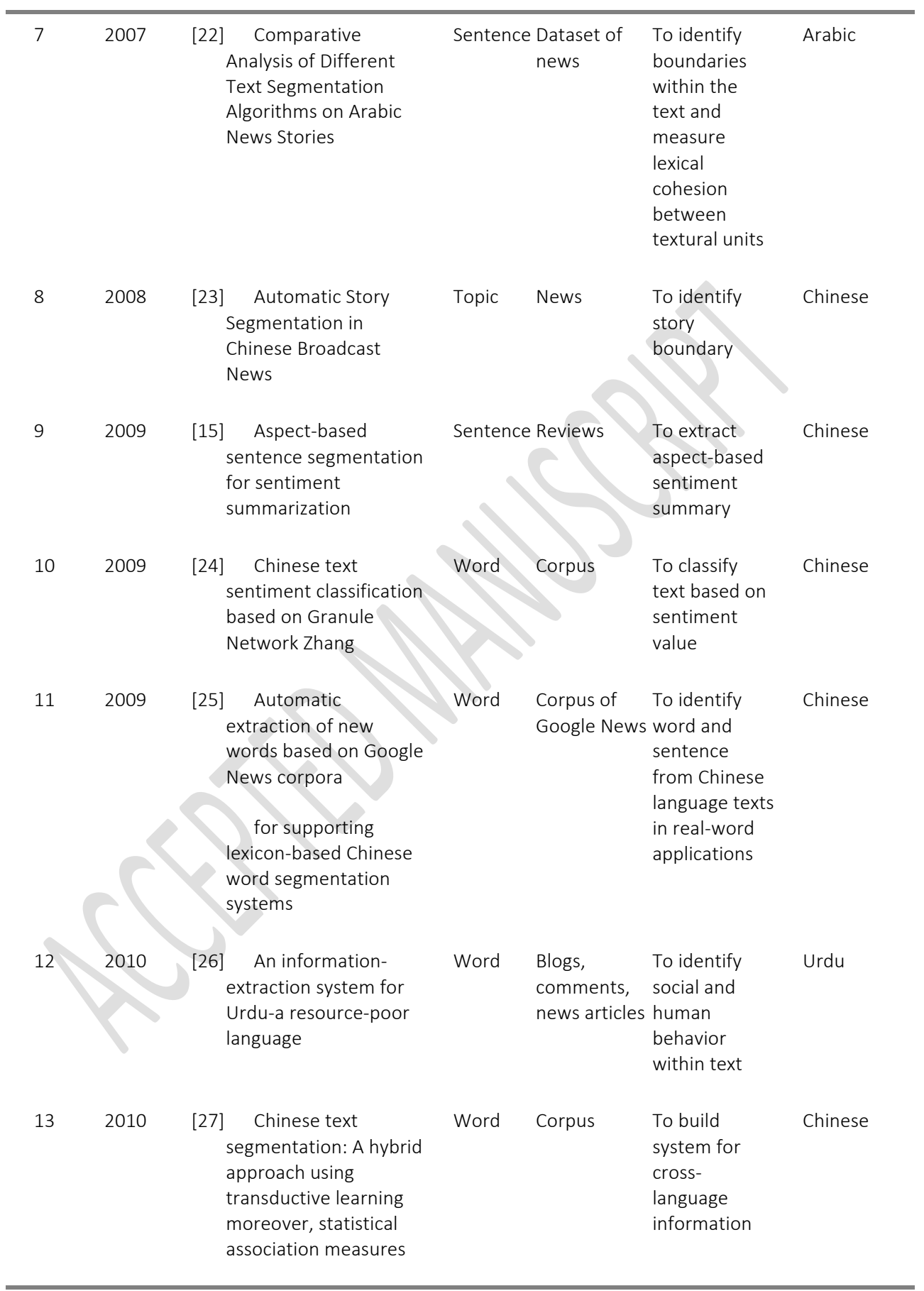




\begin{tabular}{|c|c|c|c|c|c|c|c|}
\hline 14 & 2010 & [7] & $\begin{array}{l}\text { Sentiment } \\
\text { classification for stock } \\
\text { news }\end{array}$ & Word & \multicolumn{2}{|c|}{$\begin{array}{l}\text { Chinese stock To classify } \\
\text { news } \\
\begin{array}{ll}\text { news by } \\
\text { sentiment } \\
\text { orientation }\end{array}\end{array}$} & Chinese \\
\hline 15 & 2010 & [8] & $\begin{array}{l}\text { Sentiment text } \\
\text { classification of } \\
\text { customers reviews on } \\
\text { the web based on SVM }\end{array}$ & Word & Comments & $\begin{array}{l}\text { To improve } \\
\text { accuracy of } \\
\text { sentiment } \\
\text { classification }\end{array}$ & Chinese \\
\hline 16 & 2010 & [28] & $\begin{array}{l}\text { The application of } \\
\text { text mining technology } \\
\text { in monitoring the } \\
\text { network education } \\
\text { public sentiment }\end{array}$ & Word & $\begin{array}{l}\text { Web } \\
\text { documents }\end{array}$ & $\begin{array}{l}\text { To analyze } \\
\text { sentiment in } \\
\text { text to } \\
\text { monitor } \\
\text { public }\end{array}$ & Chinese \\
\hline 17 & 2010 & & $\begin{array}{l}\text { Using text mining } \\
\text { and sentiment analysis } \\
\text { for online forums } \\
\text { hotspot detection and } \\
\text { forecast }\end{array}$ & & & $\begin{array}{l}\text { To design a } \\
\text { text } \\
\text { sentiment } \\
\text { approach }\end{array}$ & Chinese \\
\hline 18 & 2011 & & $\begin{array}{r}\text { A top } \\
\text { perspect }\end{array}$ & 10 & Corpus & $\begin{array}{l}\text { To design an } \\
\text { enhance topic } \\
\text { extraction } \\
\text { approach }\end{array}$ & English \\
\hline 19 & 2011 & & $\begin{array}{l}\text { Iterative approach } \\
\text { ext segmentation }\end{array}$ & $\begin{array}{l}\text { Topic } \\
\text { Subtopic }\end{array}$ & Articles & $\begin{array}{l}\text { To identify } \\
\text { topic and } \\
\text { subtopic } \\
\text { boundaries } \\
\text { within } \\
\text { content }\end{array}$ & English \\
\hline 20 & 2011 & [31] & $\begin{array}{l}\text { Text segmentation } \\
\text { of consumer magazinesk } \\
\text { in PDF format }\end{array}$ & $\begin{array}{l}\text { Text } \\
\text { ocks }\end{array}$ & $\begin{array}{l}\text { Articles in } \\
\text { PDF } \\
\text { documents }\end{array}$ & $\begin{array}{l}\text { To process } \\
\text { PDF } \\
\text { documents }\end{array}$ & English \\
\hline 21 & 2011 & & $\begin{array}{l}\text { Rule-based Malay } \\
\text { text segmentation tool }\end{array}$ & Sentence & Articles & $\begin{array}{l}\text { To design } \\
\text { Malay } \\
\text { sentence } \\
\text { splitter and } \\
\text { tokenizer }\end{array}$ & $\begin{array}{l}\text { Malay } \\
\text { English }\end{array}$ \\
\hline 22 & 2011 & & $\begin{array}{l}\text { A novel evaluation } \\
\text { method for }\end{array}$ & Word & Corpus & $\begin{array}{l}\text { To improve } \\
\text { word } \\
\text { segmentation }\end{array}$ & English \\
\hline
\end{tabular}




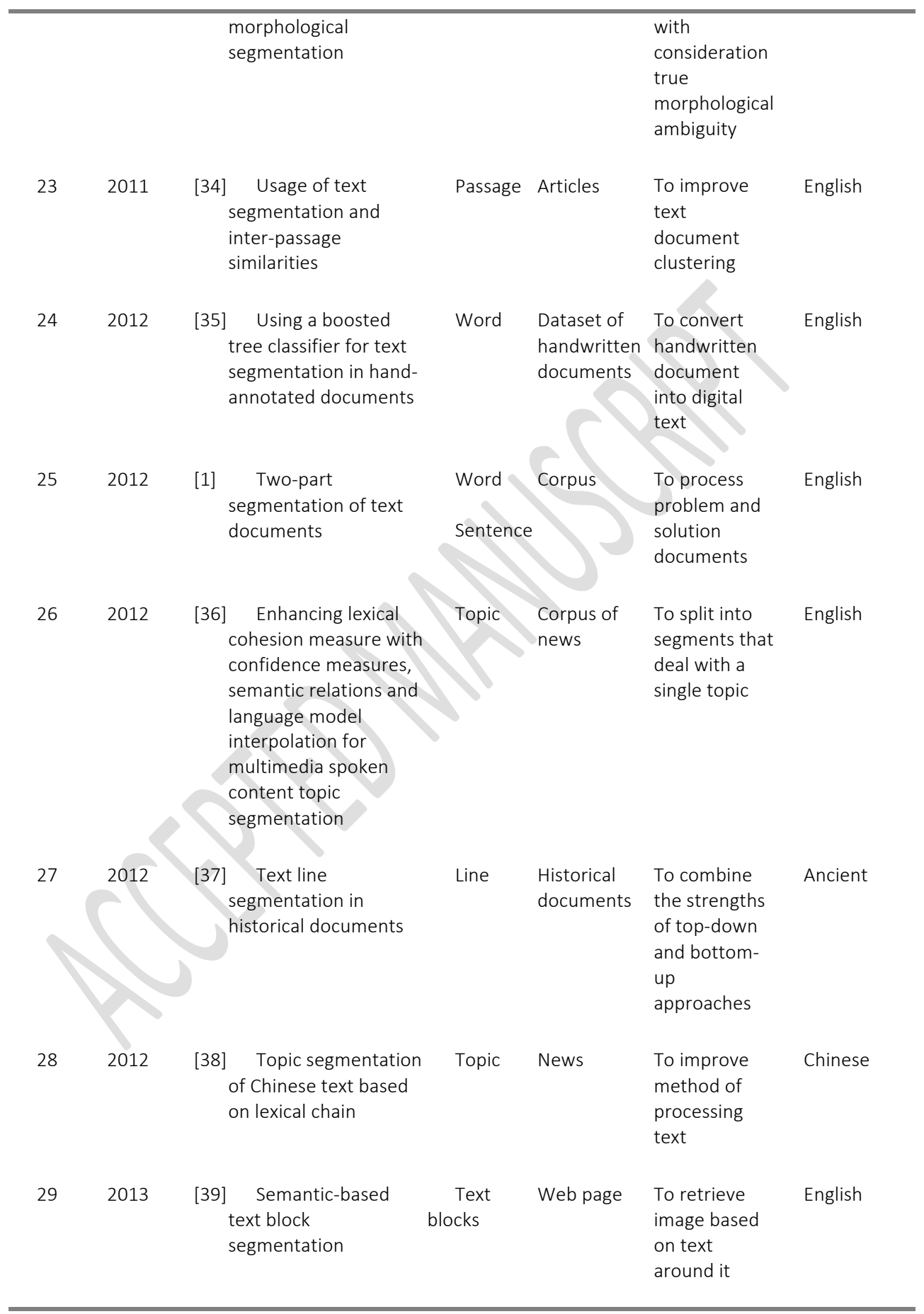




\begin{tabular}{|c|c|c|c|c|c|c|}
\hline 30 & 2013 & $\begin{array}{l}\text { [40] The first steps in } \\
\text { developing machine } \\
\text { translation of patents }\end{array}$ & Word & Dataset & $\begin{array}{l}\text { To archive the } \\
\text { translation } \\
\text { from English } \\
\text { to Russian }\end{array}$ & $\begin{array}{l}\text { Russian } \\
\text { English }\end{array}$ \\
\hline 31 & 2013 & $\begin{array}{l}\text { [41] Segmentation } \\
\text { system based on the } \\
\text { sentiments expressed } \\
\text { in the text. }\end{array}$ & $\begin{array}{l}\text { Tag } \\
\text { Word }\end{array}$ & Reviews & $\begin{array}{l}\text { To design } \\
\text { system which } \\
\text { identifies a } \\
\text { sentiment } \\
\text { expressed in } \\
\text { text }\end{array}$ & English \\
\hline 32 & 2013 & $\begin{array}{l}\text { [42] Probabilistic } \\
\text { Chinese word } \\
\text { segmentation with } \\
\text { non-local information } \\
\text { and stochastic training }\end{array}$ & $\begin{array}{l}\text { Word } \\
\text { Chara }\end{array}$ & & $\begin{array}{l}\text { To reduce } \\
\text { computationa } \\
\text { I complexity } \\
\text { of learning } \\
\text { non-local }\end{array}$ & Chinese \\
\hline 33 & 2013 & $\begin{array}{l}\text { [43] Unknown Chinese } \\
\text { word extraction based } \\
\text { on variety of } \\
\text { overlapping strings }\end{array}$ & & & $\begin{array}{l}\text { To extract } \\
\text { words from a } \\
\text { sentence and } \\
\text { improve } \\
\text { extraction of } \\
\text { unknown } \\
\text { words }\end{array}$ & Chinese \\
\hline 34 & 2013 & $\begin{array}{l}\text { [44] Text segmentation } \\
\text { for language } \\
\text { identification in Greek }\end{array}$ & $\begin{array}{l}\text { Senter } \\
\text { Topic }\end{array}$ & Forums & $\begin{array}{l}\text { To identify } \\
\text { language }\end{array}$ & Greek \\
\hline 35 & 20 & $\begin{array}{l}\text { [13] Recognition-based } \\
\text { segmentation of online } \\
\text { Arabic text recognition }\end{array}$ & Word & Dataset & $\begin{array}{l}\text { To recognize } \\
\text { Arabic text } \\
\text { within } \\
\text { handwriting }\end{array}$ & Arabic \\
\hline 36 & 2014 & $\begin{array}{l}\text { [45] Word segmentation } \\
\text { of overlapping } \\
\text { ambiguous strings } \\
\text { during Chinese reading }\end{array}$ & Chara & $\begin{array}{l}\text { rCollected } \\
\text { dataset }\end{array}$ & $\begin{array}{l}\text { To detect } \\
\text { word } \\
\text { boundaries } \\
\text { and recognize } \\
\text { the word }\end{array}$ & Chinese \\
\hline 37 & 2015 & $\begin{array}{l}\text { [46] Chinese text } \\
\text { sentiment orientation } \\
\text { identification }\end{array}$ & \multicolumn{2}{|c|}{ CharacterCorpus } & $\begin{array}{l}\text { To identify } \\
\text { sentiment in } \\
\text { the text }\end{array}$ & Chinese \\
\hline
\end{tabular}




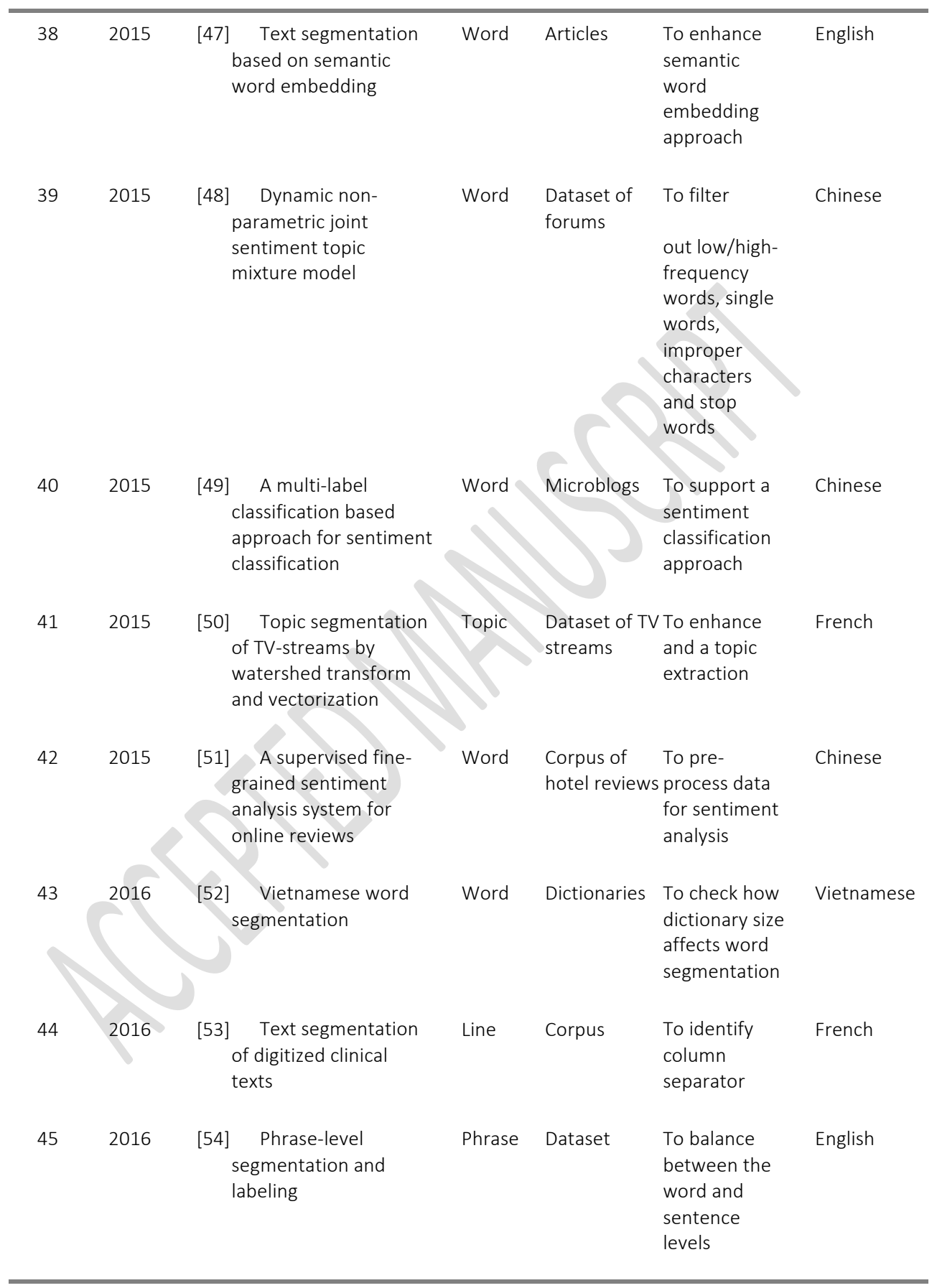




\begin{tabular}{|c|c|c|c|c|c|c|}
\hline 46 & 2016 & $\begin{array}{l}\text { [55] Akkadian word } \\
\text { segmentation }\end{array}$ & Word & Corpus & $\begin{array}{l}\text { To improve } \\
\text { the language } \\
\text { processing in } \\
\text { cuneiform }\end{array}$ & $\begin{array}{l}\text { Ancient } \\
\text { Akkadian }\end{array}$ \\
\hline 47 & 2016 & $\begin{array}{l}\text { [56] Document } \\
\text { segmentation and } \\
\text { classification into } \\
\text { musical scores and text }\end{array}$ & Word & Dataset & $\begin{array}{l}\text { To detect } \\
\text { bounding } \\
\text { boxes } \\
\text { containing the } \\
\text { musical score } \\
\text { and text }\end{array}$ & English \\
\hline 48 & 2016 & $\begin{array}{l}\text { [57] Candidate } \\
\text { document retrieval for } \\
\text { cross-lingual plagiarism } \\
\text { detection }\end{array}$ & Topic & & $\begin{array}{l}\text { To convert } \\
\text { the suspicious } \\
\text { document to } \\
\text { a set of } \\
\text { related } \\
\text { passages }\end{array}$ & $\begin{array}{l}\text { English } \\
\text { German } \\
\text { Spanish }\end{array}$ \\
\hline 49 & 2016 & $\begin{array}{l}\text { [58] Effects of text } \\
\text { segmentation on } \\
\text { reading of Chinese }\end{array}$ & & $\begin{array}{l}\text { Chinese } \\
\text { regulated } \\
\text { poems }\end{array}$ & $\begin{array}{l}\text { To monitor } \\
\text { eye } \\
\text { movements of } \\
\text { native } \\
\text { participants in } \\
\text { reading } \\
\text { Chinese } \\
\text { regulated } \\
\text { poems }\end{array}$ & Chinese \\
\hline 50 & 2017 & $\begin{array}{l}\text { [59] A new watershed } \\
\text { model-based system } \\
\text { for character } \\
\text { segmentation in } \\
\text { degraded text lines }\end{array}$ & Chara & $\begin{array}{l}\text { rDataset of } \\
\text { historical } \\
\text { document }\end{array}$ & $\begin{array}{l}\text { To } \\
\text { understand } \\
\text { the content in } \\
\text { historical } \\
\text { documents }\end{array}$ & $\begin{array}{l}\text { Indian } \\
\text { English } \\
\text { South Indian }\end{array}$ \\
\hline
\end{tabular}

Table 1 presents the summarization for the review of past years' studies where different types of segmentation are specified. As well as the reason for applying text segmentation in their methods. Doubtless, the main reason of the researchers using any text segmentation in text processing is splitting documents into segments. After the document is split, segments proceed to the different phase depending on the text analysis approach. 
In order to summarize and evaluate Table 1 in more details, pie charts and graphs are presented below. Each of the charts help to look at presented papers from different perspectives. Figure 1 concentrates on types of segment used in the studies. It is essential to evaluate segments' categorization as it is one of the main aim of this paper to consider segmentation features. Figure 2 presents a pie chart which shows variety of different languages used in evaluated papers. Lastly, Figure 3 presents a graph which indicates types of segments used in different documents' types. That can help to get a picture of which type of documents are highly used and see the another trend regarding types of segment.

Figure 1 visualizes ten different type of segments used in text segmentation from the fifty articles. Word segment is highly used compare to other types of segment. It occupied the biggest area of the chart, equivalent to a total of 26 from 50 reviewed articles. There can be several reasons to use this technique. For instance, Homburg and Chiarcos [55] described it as the most elementary and essential task in natural language processing of written language. Character segment can be categorized as word segment as well because it is mostly applied in Chinese text processing, as character segment represents single unit same as word segment in following studies[45][46][58]. Another study of [56] proposes a method for segmentation of musical documents using word segment. It detects the segments and assigns each segment to particular musical score or text. 


\section{DIFFERENT TYPES OF SEGMENTS USED FOR TEXT SEGMENTATION}

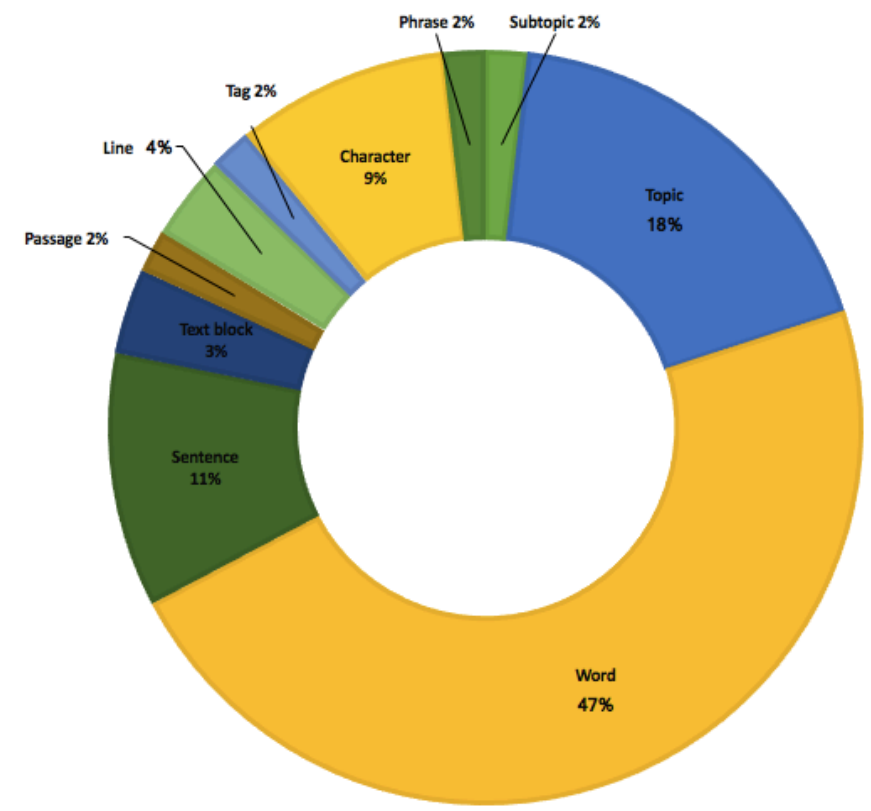

Fig. 1. Percentage of different used for text segmentation.

The second biggest area of the chart covers the use of topic segment in text processing. Topic segmentation plays an important role in data processing. For example, topic segmentation is successfully applied in tackling the problem of information overload that occur when the whole document is presented at once. Misra et al. [30] stated the reason behind splitting document could be reasonable to present only the relevant part(s) of a document. The reason they stated is that presenting the whole document without segmentation may result in previously discussed information overload. Paliwal and Pudi [34] also addressed the same problem, which led them to propose a clustering approach based on topic segmentation. Topic segmentation is popular in opinion mining area. For instance, studies of [10][30][38] used the topic as a segment. Another example of topic segmentation applied in opinion mining is a study of Claveau and Lefevre [50]. They proposed a new technique to compute similarities between candidate segments. Two corpora of TV broadcast in 
French used in evaluating of proposed technique. Furthermore, a study by Song et. al. [4] has used the topic as segment too; they proposed a novel method that includes hierarchical organization and language modeling to split the text into parts. The result of that study showed that proposed method is effective in identifying the topics in evaluated dataset of articles. Apart from opinion mining, topic segmentation is used in cross-language plagiarism detection. For instance, Ehsan and Shakery [57] applied to find and examine the candidate retrieval, where proposed approach converts the document to a set of related passages. After that, it uses a proximitybased model to retrieve documents with the best matching passages. The third most applied type of segment is a sentence. The common issue in sentence segmentation among assessed articles is identifying the boundaries between sentences [22][20].

From Table 1, it is obvious that text segmentation was applied to process text in a variety of languages including English. The pie chart on Figure 2 illustrates the numbers of percentage for each language used including English from Table 1, in order to see trend of languages used. Leading language among evaluated articles is English with the result of 38\%.

Besides English, the Chinese language is the most widely evaluated. This result shows the highest use of word segmentation technique in the process. In short, studies of [6][24][7][8][27][28][29][43][46][48][49][58] used word or character segmentation, and they are all analyzing Chinese text. One of them is study of Xia et al. [24] presents a new approach for Chinese sentiment classification based on granule network. They applied word segmentation to split sentences and later select sentimental candidate words. 


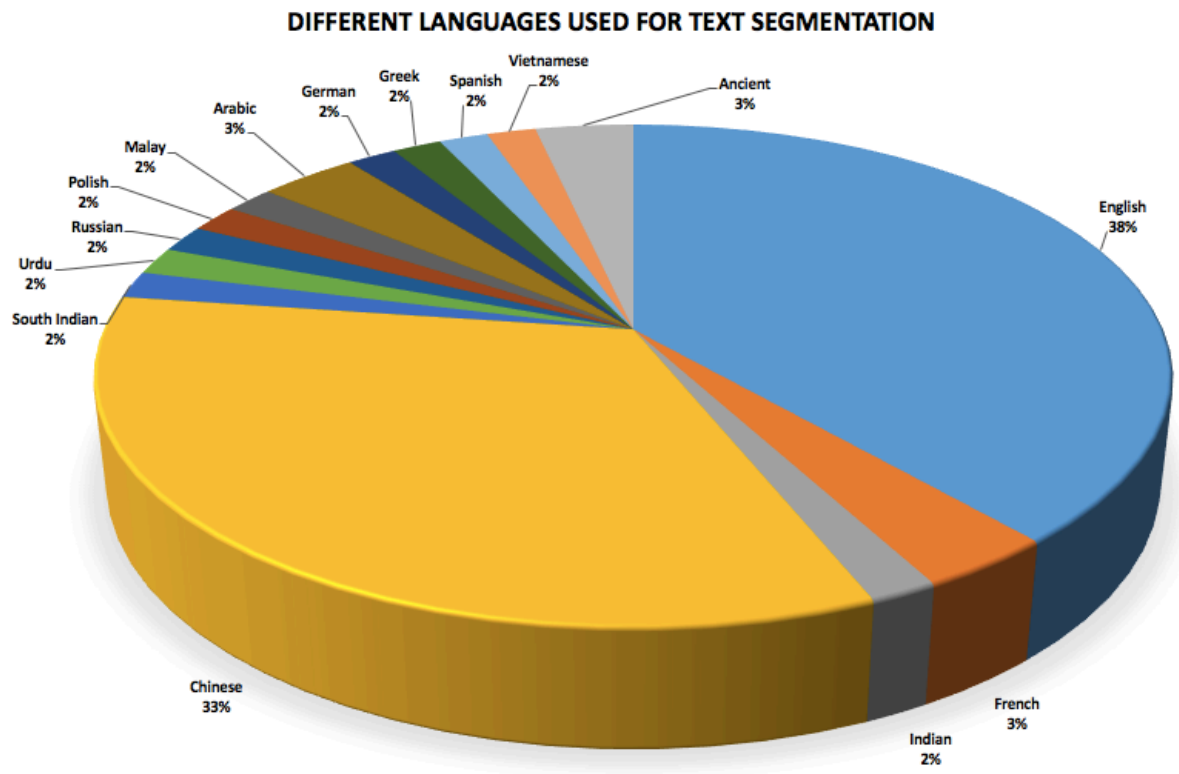

Fig. 2. Percentage of different languages used for text segmentation.

Another study of Lan at al.[46] came up with another way of analyzing Chinese text in the same area of sentiment classification. Instead of using word text segmentation, they extract sentiment value based on each character, claiming that each character can contain rich sentiment information. Another study by Hog at al. [25] applied Chinese word segmentation in information retrieval process. They built an automatic statistics-based scheme for extracting news word based on the corpora. One of the main useful features of the proposed scheme is automatic and enhanced word identification. Beside the Chinese language, there are studies which applied word segmentation for Urdu [26], Russian [40], Arabic [13], Vietnamese [52], Akkadian [55], Indian [59] and South Indian [59]. However, other studies [22][44] and [32] applied sentence segmentation to analyze Arabic, Greek, and Malay languages accordingly. The topic segmentation technique is used for processing Polish [10], Chinese [38], French [50], German [57] and Spanish [57] languages. Besides that, "line" segmentation is also applied for processing Ancient [37] and French [53] languages. As a summary, it can be seen that there is 
a trend to apply text segmentation in the analyzing text in different languages.

Different types of segments used for different types of document

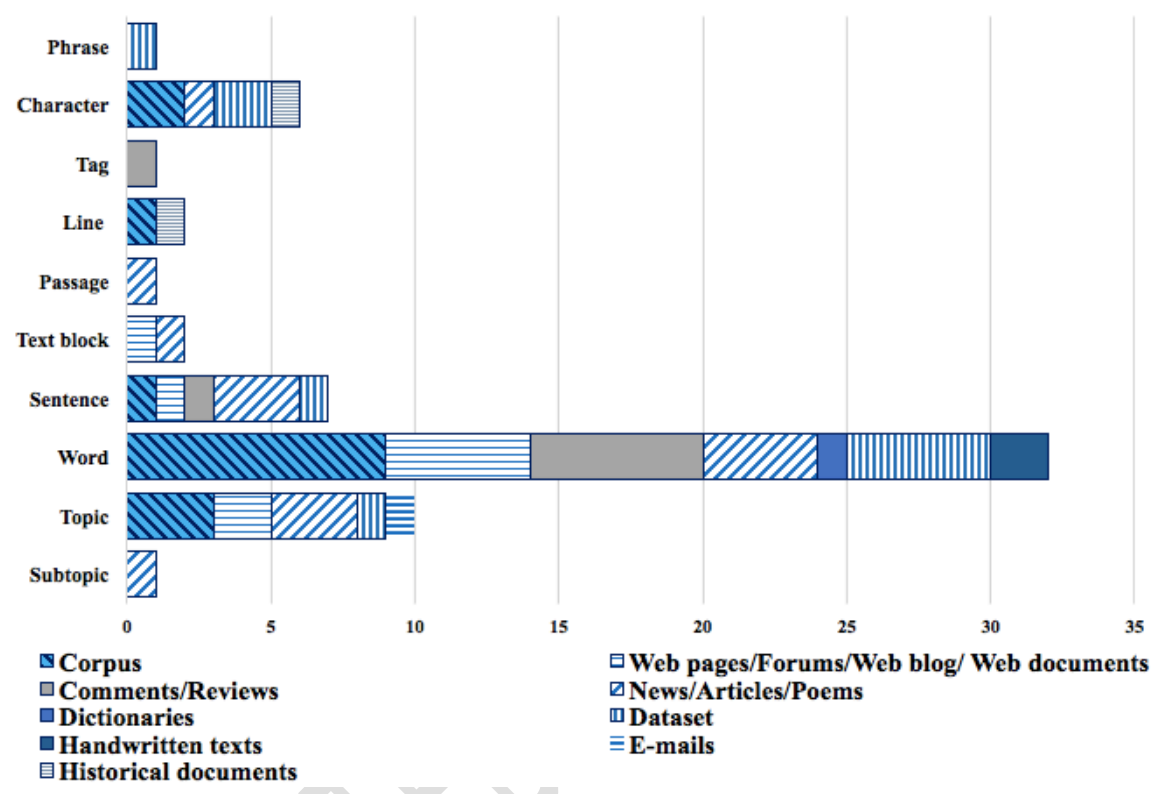

Fig. 3. Different types of segments used for different types of data.

We further identify if the different types of the document and datasets have any relationship on the selection of different type of segmentation technique. Figure 3 presents the number of percentage of each type of segments used for different types of document derived from Table 1. In this study, we categorize web pages, web blog, and web documents as the same group of documentations. After all, it is the most used type of document among all. The second widely used type of document is comments and reviews. Segments can be classified into the tag, word, sentence, topic, phrase and any information unit. 
Figure 3 concludes that word is the most used type of segment used for corpus. Furthermore, the word segment is also highly used for comments and reviews. Web documents are utilized under word, topic and sentence segments that can indicate that web documents including pages, forums and blogs take a big part in text analyzing.

\section{Discussion}

As a result, we noticed the trend of applying text and sentence segmentation in processing and analyzing different languages such as Chinese, Vietnamese, Urdu, Arabic, and Ancient languages. Besides applying text segmentation for different languages, text segmentation successfully applied in opinion mining for news, blog and stock market. Finally, after comparison between evaluated types of segments, word segment is the most used compare to another types of the segment. It can be due to the smallest size of the segment which allows more detailed analysis.

\section{Conclusion}

This paper presents a critical review of the text segmentation methods and reasons in text processing and analyzing languages, sentiment, opinions and fifty published articles for the past decade were categorized and summarized. Those articles give contributions to text processing in information retrieval, emotion extraction, sentiment and opinion mining and language detection.

Results of this study show that word as the segment is the most used compare to other types of the segment. It means that processing smaller segments can be more useful and meaningful for more detailed and deeper analyzing of the text. Different types of document are used as a dataset for the experiment. The most popular are web pages, web blog and web document following by comments and reviews. That indicates 
that information from the online users and consumers plays an important role in expressing people's emotions, opinions, and feelings.

Considering the findings of this paper, the future study can include implementation of text analysis approach using text segmentation with word segment.

Acknowledgments. We would like to thank First EAI International Conference on Computer Science and Engineering for the opportunity to present our paper and further extend it. This research paper was partially supported by Sunway University Internal Research Grant No. INTFST-IS-0114-07 and Sunway-Lancaster Grant SGSSL-FST-DCIS-0115-11.

\section{References}

1. P. D, Visweswariah K, Wiratunga N, Sani S (2012) Two-part segmentation of text documents. In: Proc. 21st ACM Int. Conf. Inf. Knowl. Manag. - CIKM '12. ACM New York, NY, Maui, p 793

2. Scaiano M, Inkpen D, Laganière R, Reinhartz A (2010) Automatic text segmentation for movie subtitles. In: Lect. Notes Comput. Sci. Springer, pp 295-298

3. Oh H, Myaeng SH, Jang M-G (2007) Semantic passage segmentation based on sentence topics for question answering. Inf Sci (Ny) 177:3696-3717.

4. Song F, Darling WM, Duric A, Kroon FW (2011) An Iterative Approach to Text Segmentation. In: 33rd Eur. Conf. IR Res. ECIR 2011. Springer Berlin Heidelberg, Dublin, pp 629-640

5. Oyedotun OK, Khashman A (2016) Document segmentation using textural features summarization and feedforward neural network. Appl Intell 45:1-15.

6. Wu Y, Zhang Y, Luo SM, Wang XJ (2007) Comprehensive information based semantic orientation identification. In: IEEE NLP-KE 2007 - Proc. Int. Conf. Nat. Lang. Process. Knowl. Eng. IEEE, Beijing, pp 274-279

7. Gao Y, Zhou L, Zhang Y, et al (2010) Sentiment classification for stock news. In: ICPCA10 - 5th Int. Conf. Pervasive Comput. Appl. IEEE, Maribor, pp 99-104

8. Xia H, Tao M, Wang Y (2010) Sentiment text classification of customers reviews on the Web based on SVM. Proc - 2010 6th Int Conf Nat Comput ICNC 2010 7:3633-3637.

9. Liu C, Wang Y, Zheng F (2006) Automatic text summarization for dialogue style. In: Proc. IEEE ICIA 2006 - 2006 IEEE Int. Conf. Inf. Acquis. IEEE, Weihai, pp 274-278

10. Osman DJ, Yearwood JL (2007) Opinion search in web logs. Conf Res Pract Inf Technol Ser 63:133-139.

11. Brants T, Chen F, Tsochantaridis I (2002) Topic-Based Document Segmentation with Probabilistic Latent Semantic Analysis. In: CIKM'02. ACM, Virginia, pp 211-218

12. Flejter D, Wieloch K, Abramowicz W (2007) Unsupervised Methods of Topical Text Segmentation for Polish. In: SIGIR'13. ACM, Dublin, pp 51-58

13. Potrus MY, Ngah UK, Ahmed BS (2014) An evolutionary harmony search algorithm with dominant point detection for recognition-based segmentation of online Arabic text recognition. Ain Shams Eng J 5:1129-1139.

14. Huang X, Peng F, Schuurmans D, et al (2003) Applying Machine Learning to Text Segmentation. Inf Retr J 6:333-362. 
15. Zhu J, Zhu M, Wang H, Tsou BK (2009) Aspect-based sentence segmentation for sentiment summarization. In: Proceeding 1st Int. CIKM Work. Top. Anal. mass Opin. - TSA '09. ACM New York, NY, USA (C)2009, Hong Kong, pp 65-72

16. Gan KH, Phang KK, Tang EK (2007) A semantic learning approach for mapping unstructured query to web resources. In: Proc. - 2006 IEEE/WIC/ACM Int. Conf. Web Intell. (WI 2006 Main Conf. Proceedings), WI'06. IEEE, Hong Kong, pp 494-497

17. Hoon GK, Wei TC (2016) Flexible Facets Generation for Faceted Search. In: First EAI Int. Conf. Comput. Sci. Eng. EAI, Penang, Malaysia, pp 1-3

18. Duan D, Qian W, Pan S, et al (2012) VISA: a Visual Sentiment Analysis System. In: Proc. 5th Int. Symp. Vis. Inf. Commun. Interact. - VINCI '12. ACM, Hangzhou, pp 22-28

19. Sun Y, Butler TS, Shafarenko A, et al (2007) Word segmentation of handwritten text using supervised classification techniques. Appl Soft Comput 7:71-88.

20. Lamprier S, Amghar T, Levrat B, Saubion F (2007) ClassStruggle: a Clustering Based Text Segmentation. In: Proc. SAC'07. ACM, Seoul, pp 600-604

21. Correa J, Dockrell JE (2007) Unconventional word segmentation in Brazilian children's early text production. Read Writ 20:815-831.

22. El-Shayeb MA, El-Beltagy SR, Rafea A (2007) Comparative Analysis of Different Text Segmentation Algorithms on Arabic News Stories. In: IEEE Int. Conf. Inf. Reuse Integr. Las Vegas, pp 441-446

23. Xie L, Zeng J, Feng W (2008) Multi-Scale TextTiling for Automatic Story Segmentation in Chinese Broadcast News. In: 4th Asia Infomation Retr. Symp. Springer Berlin Heidelberg, Harbin, pp 345-355

24. Xia Z, Suzhen W, Mingzhu X, Yixin Y (2009) Chinese text sentiment classification based on granule network. In: 2009 IEEE Int. Conf. Granul. Comput. GRC 2009. IEEE, Nanchang, pp 775-778

25. Hong CM, Chen CM, Chiu CY (2009) Automatic extraction of new words based on Google News corpora for supporting lexicon-based Chinese word segmentation systems. Expert Syst Appl 36:3641-3651.

26. Mukund S, Srihari R, Peterson E (2010) An Information-Extraction System for Urdu-A Resource-Poor Language. ACM Trans Asian Lang Inf Process 9:1-43.

27. Tsai RT-H (2010) Chinese text segmentation: A hybrid approach using transductive learning and statistical association measures. Expert Syst Appl 37:3553-3560.

28. Liu X, Zuo M, Chen L (2010) The application of text mining technology in monitoring the network education public sentiment. In: 2010 Int. Conf. Comput. Intell. Softw. Eng. IEEE, Wuhan, pp 1-4

29. Li N, Wu DD (2010) Using text mining and sentiment analysis for online forums hotspot detection and forecast. Decis Support Syst 48:354-368.

30. Misra H, Yvon F, Cappé O, Jose J (2011) Text segmentation : A topic modeling perspective. Inf Process Manag 47:528-544.

31. Fan J (2011) Text segmentation of consumer magazines in PDF format. Int Conf Doc Anal Recognition, ICDAR 794-798.

32. Ranaivo-Malançon B (2011) Building a rule-based Malay text segmentation tool. In: 2011 Int. Conf. Asian Lang. Process. IALP 2011. IEEE, Penang, pp 276-279

33. Nouri J, Yangarber R (2011) A Novel Evaluation Method for Morphological Segmentation. In: Proc. Tenth Int. Conf. Lang. Resour. Eval. (LREC 2016). European Language Resources Association (ELRA), Portoroz, pp 3102-3109

34. Paliwal S, Pudi V (2012) Investigating Usage of Text Segmentation and Inter-passage Similarities. In: Mach. Learn. Data Min. Pattern Recognit. Springer Berlin Heidelberg, Berlin, pp 555-565

35. Peng X, Setlur S, Govindaraju V, Ramachandrula S (2012) Using a boosted tree classifier for text segmentation in hand-annotated documents. Pattern Recognit Lett 33:943-950. 
36. Guinaudeau C, Gravier G, S??billot P (2012) Enhancing lexical cohesion measure with confidence measures, semantic relations and language model interpolation for multimedia spoken content topic segmentation. Comput Speech Lang 26:90-104.

37. Clausner C, Antonacopoulos A, Pletschacher S (2012) A robust hybrid approach for text line segmentation. In: 21st Int. Conf. pattern Recognit. IEEE, Tsukuba, pp 335-338

38. Ye FY, Chen Y, Luo X, et al (2012) Research on topic segmentation of Chinese text based on lexical chain. In: 12th Int. Conf. Comput. Inf. Technol. CIT 2012. IEEE, Chengdu, pp 11311136

39. Myint N, Aung M, Maung SS (2013) Semantic Based Text Block Segmentation Using WordNet. Int J Comput Commun Eng 2:601-604.

40. Kravets LG (2013) The first steps in developing machine translation of patents. World Pat Inf 35:183-186.

41. Chiru C, Teka A (2013) Sentiment-Based Text Segmentation. In: 2nd Int. Conf. Syst. Comput. Sci. IEEE, Villeneuve d'Ascq, France, pp 234-239

42. Sun X, Zhang Y, Matsuzaki T, et al (2013) Probabilistic Chinese word segmentation with nonlocal information and stochastic training. Inf Process Manag 49:626-636.

43. Ye Y, Wu Q, Li Y, et al (2013) Unknown chinese word extraction based on variety of overlapping strings. Inf Process Manag 49:497-512.

44. Fragkou P (2013) Text Segmentation for Language Identification in Greek Forums. In: Proc. Adapt. Lang. Resour. Tools Closely Relat. Lang. Lang. Var. Elsevier B.V., Hissar, pp 23-29

45. Ma G, Li X, Rayner K (2014) Word segmentation of overlapping ambiguous strings during Chinese reading. J Exp Psychol Hum Percept Perform 40:1046-1059.

46. Lan Q, Li W, Liu W (2015) Chinese Text Sentiment Orientation Identification Based on Chinese-Characters. In: Fuzzy Syst. Knowl. Discov. (FSKD), 2015 12th Int. Conf. IEEE, Zhangjiajie, pp 663-668

47. Alemi AA, Ginsparg P (2015) Text Segmentation based on Semantic Word Embeddings. In: KDD2015. ACM, Sydney, Australia, pp 1-10

48. Fu X, Yang K, Huang JZ, Cui L (2015) Dynamic non-parametric joint sentiment topic mixture model. Knowledge-Based Syst 82:102-114.

49. Liu SM, Chen J-H (2015) A multi-label classification based approach for sentiment classification. Expert Syst Appl 42:1083-1093.

50. Claveau V, Lefevre S (2015) Topic segmentation of TV-streams by watershed transform and vectorization. Comput Speech Lang 29:63-80.

51. Shi H, Zhan W, Li X (2015) A Supervised Fine-Grained Sentiment Analysis System for Online Reviews. Intell Autom Soft Comput 21:589-605.

52. Liu W, Wang L (2016) How does Dictionary Size Influence Performance of Vietnamese Word Segmentation ? In: Proc. Tenth Int. Conf. Lang. Resour. Eval. (LREC 2016). European Language Resources Association (ELRA), Portorož, Slovenia, pp 1079-1083

53. Grouin C (2016) Text segmentation of digitized clinical texts. In: Proc. Tenth Int. Conf. Lang. Resour. Eval. (LREC 2016). European Language Resources Association (ELRA), Portorož, Slovenia, pp 3592-3599

54. Logacheva V, Specia L (2016) Phrase-Level Segmentation and Labelling of Machine Translation Errors. In: Tenth Int. Conf. Lang. Resour. Eval. (LREC 2016). European Language Resources Association (ELRA), Portorož, Slovenia, pp 2240-2245

55. Homburg T, Chiarcos C (2016) Akkadian Word Segmentation. In: Proc. Tenth Int. Conf. Lang. Resour. Eval. (LREC 2016). European Language Resources Association (ELRA), Portorož, Slovenia, pp 4067-4074

56. Pedersoli F, Tzanetakis G (2016) Document segmentation and classification into musical scores and text. Int J Doc Anal Recognit 19:289-304.

57. Ehsan N, Shakery A (2016) Candidate document retrieval for cross-lingual plagiarism detection using two-level proximity information. Inf Process Manag 52:1004-1017. 
58. Qingrong C, Wentao G, Scheepers C, et al (2017) Effects of text segmentation on silent reading of Chinese regulated poems : Evidence from Eye Movements. 44:265-286.

59. Kavitha AS, Shivakumara P, Kumar GH, Lu T (2017) A new watershed model based system for character segmentation in degraded text lines. AEU - Int J Electron Commun 71:45-52. 